\title{
ANÁLISE DA COMPREENSÃO DE PAIS ACERCA DO TESTE DO PEZINHO*
}

\author{
PARENTS' UNDERSTANDING ABOUT NEWBORN SCREENING
}

\author{
Mariana $G$ Garcia** $^{*}$ \\ Eleonora A P Ferreira*** \\ Fabiana P S de Oliveira
}

\begin{abstract}
Garcia MG, Ferreira EAF, Oliveira FPSd. Análise da compreensão de pais acerca do teste do pezinho. Rev Bras Crescimento Desenvolv Hum 2007; 17(1):01-12.

Resumo: A Triagem Neonatal, mais conhecida como o Teste do Pezinho, é uma estratégia de saúde pública que visa à prevenção de seqüelas, como o retardo mental provocado por hipotireoidismo congênito e fenilcetonúria. Estas patologias apresentam-se freqüentemente assintomáticas nos primeiros meses de vida da criança. Entretanto, se forem diagnosticadas precocemente, existe alta probabilidade do tratamento prevenir suas graves consequiências. O públicoalvo da triagem são os recém-nascidos de 0 a 30 dias de vida, e os seus cuidadores primários desempenham papel crucial para que a prevenção ocorra. O objetivo desse trabalho foi fazer um levantamento das características da clientela atendida por um serviço de referência em Triagem Neonatal localizado na cidade de Belém-PA, e avaliar a compreensão dos pais e/ou cuidadores sobre a importância da realização do Teste do Pezinho. Aplicou-se um questionário para 200 participantes que concordaram em responder a um roteiro de entrevista e foi verificado se houve retorno para buscar o resultado do teste. Os resultados indicaram que a maioria dos participantes não possuía um bom entendimento sobre a importância do teste como recurso para promover prevenção em saúde da criança.
\end{abstract}

Palavras-chave: Teste do pezinho. Triagem neonatal. Psicologia pediátrica. Prevenção.

\section{INTRODUÇÃO}

Este estudo visa contribuir com informações sobre a compreensão que pais e/ou cuidadores têm acerca do Teste do Pezinho como importante elemento na identificação e na prevenção de consequiências de doenças crônicas na infância, além de investigar se havia intenção de busca pelo resultado do teste.

\section{Triagem Neonatal}

Em Saúde Pública, triagem indica a ação primária de testes aplicados em uma população cujos indivíduos apresentam alta probabilidade de desenvolver determinadas patologias. A Triagem Neonatal (TN), realizada por meio do Teste do Pezinho, tem o objetivo de rastrear e detectar patologias na população com idade de 0 a 30 dias $^{1}$.

Sua origem remonta ao final da década de 50, nos Estados Unidos, em pesquisas visando à prevenção de doença mental em recém-nascidos (RRNN). Desde então, a TN vem se desenvolvendo, incluindo novas patologias e métodos mais eficazes e capazes de identificar, além de doenças metabólicas como a fenilcetonúria, outros tipos de patologias como as hematológicas, infecciosas e genéticas ${ }^{1}$. A possibilidade de tratamento

Estudo realizado como Trabalho de Conclusão do Curso de graduação em Psicologia pela primeira autora, com a orientação da segunda e da terceira autoras na Unidade de Referência Materno Infantil e do Adolescente, Belém-PA.

** Universidade Federal do Pará, Departamento de Psicologia Social e Escolar Fone: 3201.7448 Rod. Augusto Corrêa, s/n, Núcleo do Guamá, Centro de Filosofia e Ciências Humanas CEP 66.075-900, Belém-PA.

*** End: BR 316, Km 2, Cond. City Park, Rua A, Casa 5, Guanabara, CEP: 67.013-070, Ananindeua-Pará, Fone: 9132353902 / 91-81113915 E-mail: eleonora@ufpa.br 
precoce para estas patologias torna a triagem de suma importância para estes tipos de doença, prevenindo e reduzindo a morbimortalidade na população de risco.

No Brasil, a iniciativa pioneira de implementação da TN veio da APAE de São Paulo, que desde 1976 começou a realizar a triagem neonatal para fenilcetonúria. Em 1983, no mesmo Estado, tornou-se lei estadual a obrigatoriedade da triagem neonatal para fenilcetonúria e hipotireoidismo congênito $(\mathrm{HC})^{2}$.

O Programa Nacional de Triagem Neonatal $(\text { PNTN })^{3}$ do Ministério da Saúde foi uma conquista recente, pois data de 2001, apesar de a obrigação para realização do teste para fenilcetonúria e HC estar presente na legislação federal há mais de uma década ${ }^{4}$. O histórico da TN no Brasil inclui algumas iniciativas isoladas de implantação e coberturas desiguais nos estados. Inicialmente, não existia uma uniformidade que permitisse a visualização do que realmente acontecia no Brasil, apesar de a avaliação para fenilcetonúria (1: 12000) e HC (1: 3000) $)^{3}$ fazer parte do Sistema Único de Saúde (SUS) desde 1992.

O PNTN tem como principais objetivos: "ampliar a gama de patologias triadas, cobertura de $100 \%$ dos nascidos vivos e a definição de uma abordagem mais ampla da questão" (p.8) ${ }^{1}$. Para tal, visa integrar as esferas municipal, estadual e federal, para consolidar e uniformizar o atendimento oferecido pelos Serviços de Referência em Triagem Neonatal (SRTN) credenciados. A intenção é a criação de um banco de dados nacional sobre triagem neonatal, podendo ser avaliado como está funcionando o programa no Brasil e por regiões, orientando posteriores trabalhos.

Os SRTNs podem estar habilitados em uma de três fases, sendo que exigem uma equipe multidisciplinar mínima que inclui pediatra, nutricionista, psicólogo, assistente social e endocrinologista pediátrico. Na Fase I, a TN visa à detecção de fenilcetonúria e HC; Fase II, TN para a detecção de fenilcetonúria e $\mathrm{HC}$, doença falciforme e outras hemoglobinopatias; Fase III, TN para a detecção de fenilcetonúria e HC, doença falciforme e outras hemoglobinopatias e fibrose cística ${ }^{1}$. O serviço de referência objeto deste estudo implantou a Fase I do PNTN, sendo considerado SRTN para todo o Estado do Pará.

As patologias identificadas pela triagem neonatal implicam em grandes prejuízos para a vida dos indivíduos afetados. Entretanto, seus danos podem ser reduzidos, ou até neutralizados, caso estes indivíduos recebam tratamento e acompanhamento adequados desde os primeiros meses de vida. Doenças como a fenilcetonúria e o hipotireoidismo congênito, ambas diagnosticadas pela SRTN-Pará, freqüentemente comprometem o desenvolvimento neuropsicomotor dos indivíduos, levando à deficiência mental.

O bom prognóstico das patologias identificadas pela $\mathrm{TN}$ depende da precocidade de identificação, tratamento e acompanhamento adequados desde os primeiros meses de vida. Outro fator que justifica a importância da TN, é que a maioria destas patologias só apresenta sintomatologia no decorrer dos primeiros anos de vida da criança, já comprometendo a qualidade e até mesmo a vida de indivíduos que não foram diagnosticados precocemente ${ }^{5}$.

A TN é realizada por meio do Teste do Pezinho cujos critérios para execução incluem uma equipe técnica (composta por enfermeiro e técnico de enfermagem) treinada para a coleta de sangue e o armazenamento do material, obedecendo a padrões necessários de verificação das patologias, além da responsabilidade de oferecer orientação aos pais a respeito do procedimento que será executado, assim como a finalidade do teste. As outras responsabilidades do posto de coleta incluem: (a) manter registro da realização da coleta e retirada dos resultados; (b) busca ativa; (c) enviar o material para laboratório credenciado, e (d) entrega de resultados dos exames considerados normais, garantido a documentação e registros das informações dos recém-nascidos que passaram pela triagem ${ }^{1}$.

O Manual de Normas e Técnicas de Rotinas Operacionais do $\mathrm{PNTN}^{1}$ chama atenção para as condições que podem interferir nos resultados do Teste do Pezinho, dentre as quais destacamse: (1) para a realização do teste não há a necessidade de jejum do RN e nem restrições por uso de medicamentos; (2) para a triagem de fenilce- 
tonúria é necessário aguardar pelo menos 48 horas de nascimento para a coleta de sangue, pois só após os RRNN ingerirem proteína suficiente (ex: leite materno) é que o exame pode ser realizado, caso contrário podem ser encontrados falsos normais; (3) a prematuridade e a ocorrência de transfusão de sangue no RN podem influenciar os resultados do teste para anemia falciforme e hemoglobinopatias, sendo recomendado uma coleta nos primeiros dias de vida e outra coleta após 90 dias para confirmação do resultado.

\section{Prevenção em saúde: algumas questões}

A expectativa de vida ao longo do século $\mathrm{XX}$ aumentou consideravelmente em todo mundo, especialmente nos países com bons índices de desenvolvimento. Uma série de eventos está diretamente envolvida nessa nova configuração como o desenvolvimento tecnológico da Medicina com vacinas, medicamentos e serviços de prevenção para detecção precoce de doenças, dentre outros ${ }^{6}$.

O processo saúde-doença é multideterminado, abrangendo fatores biológicos, sociais e psicológicos. Apesar de ainda existir um enfoque curativo de controle de doenças na área médica, o campo da prevenção, principalmente de doenças crônicas, tem se mostrado valioso como um foco na promoção de saúde e qualidade de vida ${ }^{7}$. Segundo WITTER ${ }^{8}$ “... prevenir implica em aprender ou modificar comportamentos, hábitos e estilos de vida" (p. 217).

Um sistema proposto desde 1957 pela Comissão de Doenças Crônicas dos Estados Unidos considera que existem três tipos de prevenção: (1) a prevenção primária, que corresponde à redução do número de casos novos (incidência) de uma desordem ou doença; (2) prevenção secundária, que se refere à redução do índice de casos e desordens já estabelecidas (prevalência) na população, e (3) prevenção terciária, que corresponde à redução de incapacidades associadas com uma desordem ou doença existente ${ }^{9}$.

Uma ampliação da definição de prevenção primária proposta por Wallack e Winkleby ${ }^{10}$ apresenta três dimensões que incluem: (1) a promoção da saúde, direcionada a pessoas que se apresentam saudáveis, e baseia-se em tentativas de promover habilidades e informação que conduzam ao desenvolvimento e manutenção de estilos de vida saudáveis; (2) a prevenção de doenças, que busca identificar pessoas em risco para problemas particulares e fornecer serviços específicos para prevenir o agravamento desses problemas, e (3) a proteção de saúde, que envolve as duas anteriores, incluindo estratégias de responsabilidade de órgãos governamentais, consistindo em estratégias passivas, através das quais a pessoa não precisa necessariamente emitir qualquer ação para ser protegida, como o tratamento do suprimento de água, a pasteurização do leite e o saneamento básico.

$\mathrm{O}$ enfoque em somente uma dessas dimensões, principalmente na promoção da saúde, desconsidera outros aspectos como fatores ambientais e alta prevalência de doenças. Todas as dimensões da prevenção primária, assim como a prevenção secundária e a terciária são práticas importantes para promover a qualidade de vida na sociedade e, cada vez mais, são demonstradas suas vantagens em relação ao custo- benefício de somente se utilizar a promoção de práticas curativas 9 .

Para práticas de prevenção efetivas, existe a necessidade de interdisciplinaridade e de princípios que norteiem a prevenção enquanto uma ação que responda a condições de forma relacional, tendo em vista a complexidade de cada situação. Berlinguer ${ }^{11}$ aponta três princípios éticos da prevenção: (a) virtude antecipatória, seria a capacidade de agir antes que algum dano aconteça, preconizando o desenvolvimento pleno da vida de cada indivíduo e assim da espécie humana; (b) universalidade, todos os cidadãos devem ter garantidos direitos iguais em relação à saúde e ao acesso a serviços de diagnóstico e tratamento, e (c) capacidade de atenuar conflitos de interesses e valores inerentes à atividade dos profissionais e das instituições de saúde, desviando do enfoque somente na doença que tradicionalmente alimenta esse mercado.

A TN é um programa de prevenção para conseqüências de doenças que não possuem cura, porém com um prognóstico bom se tratadas desde 
o período neonatal. Sua relevância e efetividade têm sido apontadas pela Organização Mundial de Saúde para a redução da incidência da deficiência mental, principalmente em países em desenvolvimento ${ }^{1}$.

A complexidade das variáveis envolvidas, como o período de coleta do teste até 30 dias, coloca em risco a efetividade da $\mathrm{TN}$ e, nesse contexto, a informação fornecida aos familiares durante o período pré-natal sobre a importância da triagem se torna crucial.

A informação fornecida pelos profissionais, que vão atuar diretamente com os pais na ocasião do nascimento, é, por exemplo, uma variável que pode aumentar a probabilidade destes pais terem compreensão adequada da importância da TN e assim levarem seus filhos para realização do Teste do Pezinho no tempo adequado. A desinformação, tanto por parte dos profissionais como dos pais, pode influenciar na realização ou não do teste. Algumas consequiências da desinformação podem ser observadas em "mal-entendimentos" relatados por pais, como o medo de machucar o bebê, ou de acreditar que já tenha sido feito o teste no RN por conta do "carimbo do pé" (isto é, a impressão plantar rotineiramente realizada na maternidade) e, por conseguinte, não se dirigem ao posto de coleta após a alta da maternidade.

Com tudo isso, faz-se necessária uma análise de como as informações e instruções, veiculadas informalmente, por meio de campanhas na mídia ou por programas de prevenção propriamente ditos, chegam à população, com o intuito de enfatizar os benefícios da adoção de comportamentos preventivos e de promoção de saúde.

\section{O modelo analítico-comportamental e o seguimento de instruções médicas}

A análise do comportamento é uma abordagem da Psicologia que tem como base o estudo das relações funcionais entre organismo e ambiente. Aplicada à área de saúde, a abordagem analítico-comportamental traz contribuições quando esclarece sobre variáveis que controlam os comportamentos adequados e inadequados do indivíduo, como regras e auto-regras, enfatizando a função entre o estilo de vida, dos hábitos e das habilidades do indivíduo na modificação de comportamentos relacionados à promoção de saúde ${ }^{7}$.

O modelo analítico-comportamental colabora na medida em que possibilita a análise funcional do problema em termos de uma relação organismo-ambiente, facilitando o planejamento, a implementação e avaliação de programas de intervenção que promovam comportamentos adequados na prevenção e manutenção da saúde 9 . Guimarães ${ }^{7}$ afirma que "a análise funcional entre variáveis ambientais e comportamentais, utilizada na análise comportamental aplicada, representa um modelo metodológico promissor para a compreensão do processo de mediação entre variáveis biopsicossociais e saúde" (p.26).

Em uma leitura analítico-comportamental, o comportamento pode ser controlado tanto por contingências como por regras. $\mathrm{O}$ controle por contingências ocorre quando na história do indivíduo o comportamento foi conseqüenciado de determinada forma, por reforçamento ou por punição, alterando a probabilidade de ocorrência deste comportamento no futuro. O controle por regras implica em o organismo se comportar sob o controle de antecedentes verbais que especificam as conseqüências que ocorrerão caso o indivíduo se comporte de determinada maneira ${ }^{12}$.

A adesão a um programa de TN pode ser considerada como um comportamento controlado por antecedentes verbais, ou seja, por regras. As pessoas não entram em contato com o problema de saúde do RN para então poder procurar o Teste do Pezinho; instruções (regras específicas) são fornecidas aos cuidadores para que eles procurem a TN, do contrário, as crianças podem vir a ter problemas de saúde, caso a patologia não seja identificada a tempo de iniciar o tratamento preventivo.

A literatura aponta que o comportamento governado por regras nem sempre é seguido imediatamente pelas consequiências descritas nas regras. No caso da área da saúde, os sintomas de algumas doenças identificadas pelo Teste do Pezinho, como o HC, não são observados imediatamente, levando os pais a duvidarem da real necessidade de realização do teste na criança. Entretanto, pelas funções indicadas nas regras, o comportamento pode ficar sob controle de 
conseqüências mediadas socialmente ${ }^{13}$. Por exemplo, o comportamento de seguir instruções fornecidas pelo médico é reforçado desde cedo pela sociedade, pois a "autoridade" de profissionais de saúde é uma regra social amplamente aceita.

\section{OBJETIVOS}

\section{Objetivos gerais}

Foi realizado um estudo descritivo, com delineamento transversal, com o principal objetivo de investigar o entendimento que pais e/ou cuidadores têm acerca da TN, mais especificamente sobre o Teste do Pezinho, como importante elemento na prevenção de conseqüências graves ocasionadas por doenças crônicas em suas crianças. Com base na literatura sobre comportamento governado por regras e por contingências, procurou-se analisar a adesão dos pais ou responsáveis à instrução de busca pela realização do teste.

\section{Objetivos específicos}

- Descrever a caracterização sócio-demográfica da clientela que realiza a TN, incluindo a criança e seu principal acompanhante.

- Investigar as principais variáveis envolvidas na adesão à instrução de realizar a TN e de buscar o resultado do Teste do Pezinho como elemento de proteção à saúde e ao desenvolvimento da criança.

\section{METODO}

\section{Participantes}

Participaram deste estudo duzentos pais e/ ou cuidadores, dentre os quais foi evidenciada a mãe $(n=182,91 \%)$ como acompanhante principal da criança. Além da mãe, 12 participantes (6\%) eram os pais e $6(3 \%)$ eram as avós.

A faixa etária mais freqüente $(n=63,32 \%)$ dos participantes correspondeu às idades entre 19 a 23 anos, dentre os quais 3 eram do sexo masculino. No intervalo de 14 a 18 anos, foram encontrados $58(29 \%)$ acompanhantes sendo todos as mães; no intervalo de 24 a 28 anos foram identificadas 35 (18\%) mães e $6(3 \%)$ pais; entre 29 a 33 anos, $12(6 \%)$ eram as mães e $2(1 \%)$ os pais. Acima de 34 anos, a maioria $(\mathrm{n}=14,7 \%)$ eram mães, 4 (2\%) eram pais e $6(3 \%)$ eram avós.

A maior parte dos entrevistados $(n=77$, $39 \%$ ) não havia concluído o ensino fundamental; em seguida, 47 (24\%) possuíam o ensino médio completo, 40 (20\%) não haviam concluído o ensino médio, 24 (12\%) possuíam o ensino fundamental completo, 7 (4\%) possuíam o ensino superior completo e $5(3 \%)$ possuíam o ensino superior incompleto.

\section{Local da coleta de dados}

A unidade de referência na qual este estudo foi conduzido realiza a TN de segunda a sextafeira, no horário de sete às dez da manhã, geralmente entregando de 10 a 15 fichas para o atendimento ao público em geral. Para que a criança possa fazer o Teste do Pezinho, o responsável deve responder perguntas de uma ficha cadastral, na qual são registradas informações cruciais para que, no caso de alguma alteração no exame ser identificada pelo laboratório, a criança seja localizada imediatamente. Também são obtidas algumas informações que podem influenciar diretamente no resultado do exame, como se a criança foi amamentada, a ocorrência de prematuridade, e se ficou internada e/ou fez transfusão de sangue. Depois de fazer o registro da criança, o responsável recebe um impresso com a data a partir da qual estará disponível o resultado do teste.

Após o preenchimento do cadastro, o teste é realizado em uma sala reservada para a coleta de material, por uma enfermeira ou auxiliar de enfermagem. Antes da realização do teste, o responsável recebe orientações sobre como segurar o bebê: em pé, apoiando no ombro, bem firme, deixando livre as pernas e os pés ("posição de arroto"). Após o preenchimento do papel filtro com o sangue do bebê, o responsável recebe orientações para não aplicar nenhum medicamento no local, levar a criança para tomar as vacinas de rotina e amamentá-lo se o bebê estiver chorando. 
Os resultados são entregues de segunda a quintafeira, depois das dez horas da manhã, no mesmo local em que foi realizado o teste. O tempo médio para a entrega do resultado é de um mês.

\section{Materiais e recursos utilizados para a coleta de dados:}

Foram utilizados: (1) Termo de Consentimento Livre e Esclarecido (seguindo as orientações da Resolução 196/CNS) para o acompanhante principal da criança, e (2) um roteiro de entrevista semi-estruturado que incluía perguntas sobre dados sócio-demográficos, questões sobre o Teste do Pezinho, com perguntas semi-abertas aplicadas antes da realização do teste e perguntas abertas aplicadas após a realização do teste. Os instrumentos foram aplicados pela autora principal deste estudo, com a colaboração de duas alunas do curso de graduação em Psicologia, previamente treinadas no procedimento de coleta de dados.

\section{Procedimento de coleta de dados}

Todos os responsáveis que se encontravam na sala de espera da unidade de referência, aguardando a realização do Teste do Pezinho, foram abordados pelas pesquisadoras, que explicavam os objetivos do estudo, pedindo a colaboração voluntária. Os que concordavam em participar eram solicitados a assinar o Termo de Consentimento. $\mathrm{O}$ roteiro de entrevista era aplicado por uma pesquisadora em dois momentos: antes do teste e após o teste. Após o período de dois meses da realização das entrevistas, verificou-se, nos registros da unidade, quais os pais ou responsáveis, dentre os que participaram do estudo, haviam buscado o resultado do teste.

\section{Análise de dados}

Os duzentos questionários aplicados foram armazenados em um banco de dados no programa Excel. Dividiram-se os dados em: (1) sóciodemográficos, caracterizando as crianças e os informantes, e (2) informações sobre o Teste do Pezinho. Foram utilizados os Testes Estatísticos: Qui-Quadrado para proporções esperadas desiguais, Teste de Kolmogorov-Sminorv para duas amostras independentes e Teste $t$ de Student, por meio do programa BioEstat versão 3.0 ${ }^{14}$.

\section{RESULTADOS}

\section{Renda e ocupação dos pais e/ou cuidadores}

A renda mensal dos participantes (Figura.1) indica que a população atendida na unidade de referência na qual este estudo foi realizado caracteriza-se por ser de baixa renda, com a maioria (36\%) recebendo até um salário mínimo mensalmente.

Figura 1. Distribuição percentual da renda familiar mensal relatada pelos pais e/ou cuidadores de crianças que realizaram o Teste do Pezinho na unidade de referência.

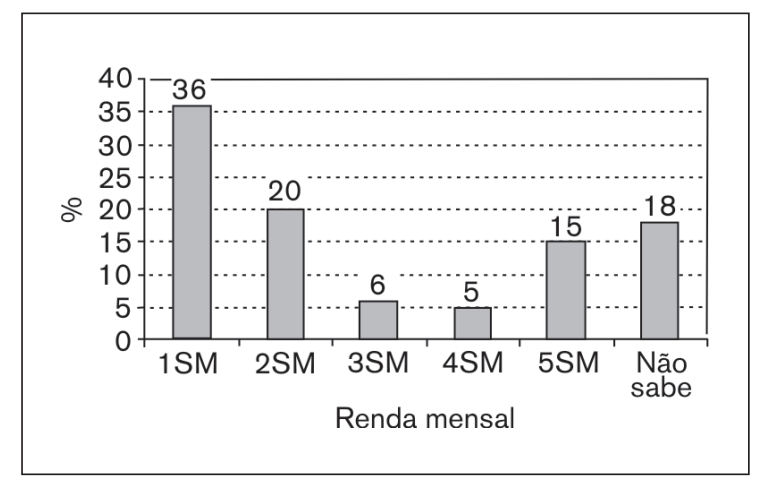

Quanto à ocupação dos cuidadores, observou-se que as mães $(n=182)$ eram em sua maioria donas-de-casa (72 de 182) ou estudantes (60 de 182). Com relação aos poucos pais entrevistados $(n=12)$, houve presença de assalariados $(n=5)$ e autônomos $(n=6)$, além de um estudante. Todas as seis avós entrevistadas recebiam remuneração, ou como pensionista $(n=5)$ ou como autônoma $(n=1)$.

\section{Local de moradia}

Houve prevalência de cuidadores provenientes da capital $(n=184,92 \%)$. A análise estatística, realizada através do Teste Qui-Quadrado: proporções esperadas desiguais, demonstrou que a diferença foi muito significativa $(\mathrm{p}<0.00)$. 
Um resultado importante a ser destacado é que todos os RRNN, cujos pais e/ou cuidadores foram os participantes deste estudo, nasceram em hospitais da cidade de Belém ou de sua região metropolitana, mesmo aqueles que residiam em cidades do interior do Estado, distantes da capital.

\section{Condição clínica da criança ao nascer, tempo de hospitalização e intervalo identificado para a realização do Teste do Pezinho}

Procurou-se relacionar a condição clínica do $\mathrm{RN}$ ao nascer, o tipo de parto, o tempo em que este permaneceu no hospital após o nascimento e $o$ intervalo identificado entre o nascimento e a data em que o RN foi submetido ao Teste do Pezinho (Figura 2).

Figura 2. Número de RRNN de acordo com o parto, o tempo de hospitalização e o intervalo entre o nascimento e a realização do Teste do Pezinho.

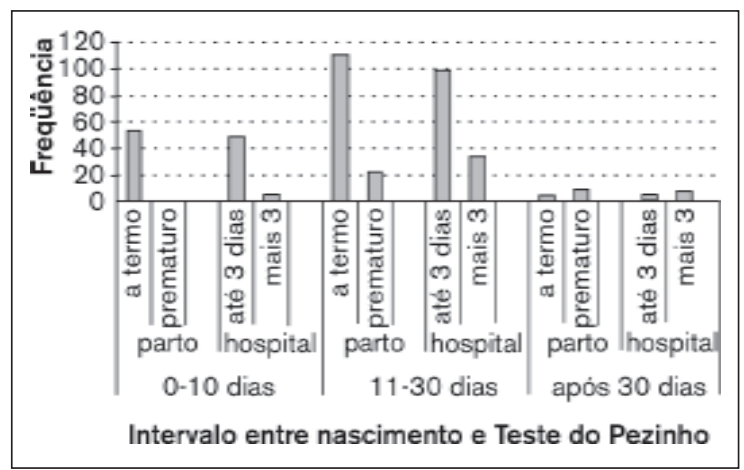

Todas as $54(27 \%)$ crianças que realizaram a TN até 10 dias de nascimento nasceram de parto a termo. Dentre essas crianças, 46 (85\% em 54) não apresentaram qualquer intercorrência ao nascer, 3 (6\% em 54) ficaram internadas e 5 (9\% em 54) apresentaram outros problemas como icterícia e problemas com a saúde das mães do RN. Quanto à alta hospitalar, 49 (91\% em 54) receberam alta até três dias de nascimento, enquanto que as demais crianças receberam alta a partir desse prazo.

Dentre as 133 crianças que realizaram a TN entre 11 e 30 dias, 111 ( $84 \%$ em 133) nasceram a termo enquanto que $22(16 \%$ em 133$)$ tiveram parto prematuro, e 104 (78\% em 133) não apresentaram intercorrências ao nascer. Dentre as 29 crianças que apresentaram intercorrências, 15 (52\% em 29) precisaram ser internadas e 14 (48\% em 29) apresentaram outros problemas como os descritos acima. Quanto à alta hospitalar, 99 (75\% em 133) saíram do hospital entre um a três dias de nascidos.

Dentre as 13 crianças que realizaram a TN após 30 dias de nascimento, 9 (70\% em 13) nasceram de parto prematuro e 4 (30\% em 13$)$ nasceram a termo. Destas crianças $11(85 \%$ em 13) apresentaram intercorrências, das quais 8 (73\% em 11) precisaram de transfusão sanguínea, 1 (9\% em 11) foi internada em unidade de terapia intensiva e 2 (18\% em 11 ) apresentaram outros problemas. Quanto à alta hospitalar, $5(39 \% \mathrm{em}$ 13) saíram do hospital até três dias, enquanto que 8 (61\% em 13) saíram a partir de três dias de nascimento.

Todos os RRNN haviam nascido em instituições hospitalares. Como a maior parte recebeu alta até três dias $(n=153)$, esta variável por si só não justificaria o intervalo superior a 10 dias para a realização do Teste do Pezinho realizado por 146 RRNN.

Pressupondo-se que os valores esperados para a realização da $\mathrm{TN}$ fossem equivalentes, foi realizada uma análise estatística com o Teste do Qui-Quadrado que demonstrou que a diferença foi estatisticamente significativa ( $\mathrm{p}<$ 0.05), havendo predominância de pacientes que realizaram a triagem após os 10 primeiros dias de nascimento.

\section{Motivos que levaram os cuidadores à realização da TN nessa unidade}

Quanto aos motivos apontados pelos cuidadores a levarem suas crianças à unidade de referência em questão, observou-se que: 115 (58\%) realizaram a $\mathrm{TN}$ nesta unidade por indicação da maternidade ou hospital onde o bebê nasceu; 44 (22\%) compareceram por livre escolha, por motivos pessoais como proximidade do local ou confiança na unidade a partir de recomendações de terceiros; 41 (20\%) escolheram a unidade porque já faziam algum tipo de atendimento na própria instituição, preferencialmente o pré-natal. 


\section{Conhecimento dos pais elou cuidadores sobre o Teste do Pezinho e TN}

Sobre o conhecimento de como é realizado o Teste do Pezinho, incluindo respostas positivas do tipo: "o teste fura o pé da criança", "é uma furadinha no pé", "tira sangue do pé e preenche cinco bolinhas", $170(85 \%)$ souberam descrever. Entretanto, $15 \%(n=30)$ não demonstraram conhecer como era feito o teste na criança, mesmo quando o entrevistador perguntava de maneira simplificada.

Resultados importantes foram obtidos em relação ao conhecimento sobre o quê aconteceria se o resultado do teste indicasse alguma alteração. Somente $26 \%(n=52)$ dos participantes souberam dizer que, caso o resultado do teste indicasse a presença de alguma doença, o RN teria um acompanhamento especializado ou receberia tratamento preventivo.

Outro resultado obtido indica que $56 \%$ dos participantes $(n=112)$, quando questionados se gostariam de receber mais algum esclarecimento sobre o teste, disseram que não precisariam de mais nenhum esclarecimento. Os $44 \%$ que gostariam de ter mais algum esclarecimento, queriam em geral respostas para as perguntas: "Quais as doenças que podem ser evitadas? Se der positivo, o que fazer? Para que serve exatamente?".

Mesmo os participantes que responderam que não haviam recebido qualquer informação sobre a finalidade do Teste do Pezinho após a realização do mesmo, quando questionados se gostariam de saber mais informações sobre o teste, responderam que não seria necessário $(43 \%)$.

Quanto à necessidade de realizar o teste, 90\% dos entrevistados respondeu que achava necessário, com respostas do tipo "é importante para a saúde do meu filho". A própria realização da entrevista pode ter sido uma variável que influenciou na obtenção deste resultado em relação à importância do teste. Mesmo assim, 10\% dos entrevistados não souberam dizer se achavam o teste importante como recurso para a promoção da saúde da criança.

\section{Escolaridade dos pais elou cuidadores $e$ conhecimento sobre a TN}

Considerando-se que a escolaridade dos pais e/ou cuidadores pode ser uma variável que venha a interferir na compreensão sobre a importância do teste e na adesão destes ao programa de TN, os resultados foram analisados por meio do Teste de Kolmogorov-Smirnov, tendo como $\mathrm{H}_{0:}$ o conhecimento do cuidador sobre a TN independe do seu nível de escolaridade e $\mathrm{H}_{1}$ : o conhecimento do cuidador sobre a TN depende do seu nível de escolaridade. Os resultados demonstraram que a diferença entre as duas amostras foi estatisticamente significativa $(\mathrm{p}<0.05)$, ou seja, a maioria dos cuidadores não tinha conhecimento sobre a TN, independente do nível de escolaridade.

\section{Informações recebidas pelos pais elou cuidadores após a realização da TN}

Após a realização da TN, 94\% $(\mathrm{n}=188)$ dos entrevistados no pós-teste disseram que a enfermeira não forneceu informações sobre o teste em si, que esta informou apenas sobre os procedimentos de como segurar o bebê para coletar o sangue e sobre cuidados com o local onde fora realizada a coleta. Os $6 \%$ restantes $(n=12)$ responderam que a enfermeira explicou dúvidas sobre quais doenças o teste identificava; porém, quando questionadas sobre essas doenças, não souberam dizer. Somente 7 participantes $(3,5 \%)$ souberam identificar corretamente pelo menos uma dentre as patologias rastreadas por meio da $\mathrm{TN}$.

A partir do Teste $t$ de Student para duas amostras relacionadas, a análise indicou que a diferença entre os informantes que tinham conhecimento sobre a TN antes de sua realização e após a sua realização foi estatisticamente muito significativa $(p<0.00)$, ou seja, a maioria dos cuidadores não tinha conhecimento sobre a TN mesmo após a sua realização.

\section{Recomendação da realização do Teste do Pezinho a outros cuidadores}

Quando os participantes foram questionados sobre o que diriam para outra mãe/cuidador 
de um RN sobre o Teste do Pezinho, $10 \%$ não souberam descrever o que diriam. Os $90 \%$ que responderam, dariam algum conselho, sendo que a grande maioria apontava que o teste era importante para a saúde do bebê. Entretanto, observouse em alguns relatos que, após o procedimento de coleta de sangue, alguns participantes destacaram as contingências aversivas relacionadas ao sofrimento do bebê durante a realização do teste. Alguns depoimentos indicaram a possibilidade dos participantes descreverem a outro cuidador contingências como: "que [o teste] é horrível; que isso é uma tortura; que é uma 'droga' esse teste; acho importante, mas não gosto porque a criança chora; que [a criança] chora muito e mesmo assim tem que apertar a criança; dói um pouco na criança, mas tem que ser feito, pois é para o bem dela".

\section{Intenção de buscar o resultado da TN}

Em relação à intenção de buscar o resultado, considerada neste estudo como uma importante variável indicativa da compreensão dos pais sobre a relevância do teste, $8 \%(\mathrm{n}=16)$ dos participantes responderam que não sabiam se iriam buscar o resultado do teste; entretanto, destes, somente $2 \%$ $(\mathrm{n}=4)$ ainda não haviam buscado o resultado do teste após dois meses da realização do mesmo.

No total, isto é, entre os que disseram que iriam buscar $(\mathrm{n}=184)$ e os que disseram que não sabiam se iriam buscar o resultado, $28 \%(\mathrm{n}=56)$ não tinham ido buscar o resultado do teste no período de um mês após a data prevista para o último dia de coleta de dados.

\section{DISCUSSÃO}

Foi evidenciado na pesquisa que a maioria das crianças que tiveram os seus cuidadores entrevistados eram provenientes da capital $(92 \%$ dos casos). Ao se considerar que esta unidade é referência em TN para o Estado do Pará, supõese que esse resultado pode ter sido encontrado devido a: (a) o alto custo para o cuidador em se deslocar de seu local de moradia para a realização da TN em Belém; (b) a existência de serviços de coleta para o Teste do Pezinho no interior do
Estado, como preconiza o PTNN, o que não foi investigado neste estudo, além de (c) a possibilidade de haver outros locais de coleta de TN na cidade de Belém, o que também não foi investigado.

Na seleção da amostra para este estudo, não se considerou a proporção entre moradores da capital e moradores do interior em virtude desta variável não ter sido destacada como relevante para a análise dos resultados. De todo modo, ressalta-se aqui a importância da expansão deste serviço às cidades do interior do Estado do Pará.

Quanto aos motivos que levaram os cuidadores à realização da TN na unidade de referência objeto deste estudo, observou-se que, a predominância de cuidadores que compareceram a esse local a partir da indicação do hospital onde o bebê nasceu mostra a importância da efetividade das informações repassadas aos pais, não somente durante o período de acompanhamento no prénatal, mas também no perinatal, ressaltando-se na alta hospitalar.

Entretanto, deve-se levar em conta que, mesmo com os pais procurando a referida unidade para a realização da $\mathrm{TN}$, a partir da recomendação de profissionais ou de terceiros, o intervalo utilizado para a sua realização foi estatisticamente acima do considerado adequado pela literatura para a identificação de algumas patologias, como o HC. Isto pode ser preocupante se for considerado o tempo de retorno do resultado do teste, que no caso poderia chegar até a trinta dias, prejudicando o início ideal para o tratamento preventivo como vem sendo destacado na literatura ${ }^{4}$.

Ficou evidente que a maioria dos cuidadores não possuía conhecimento sobre a forma como é realizado o Teste do Pezinho, sobre sua finalidade, nem as patologias que são identificadas através deste teste, independente do grau de parentesco com a criança, do nível de escolaridade ou da faixa etária do informante. A falta de conhecimento adequado sobre a TN demonstrada na pesquisa pode sinalizar que, talvez, o tipo de instrução recebida esteja relacionado apenas à necessidade de fazer o teste, uma regra descrita por uma "autoridade socialmente valorizada" como o médico, corroborando o que vem sendo indicado na literatura sobre controle do comportamento por meio de regras ${ }^{11}$. 
De acordo com os resultados obtidos, a noção de prevenção que acompanha a TN parece estar estabelecida enquanto uma regra ampla que especifica somente parte da contingência em vigor: "faça o teste porque é para o bem do seu filho", mas sem especificar todas as conseqüências e procedimentos que estão envolvidos nas etapas da triagem. Entretanto, se o cuidador não fizer uma análise das justificativas associadas ao comportamento de realizar a TN, o comportamento de seguir esta regra pode ficar comprometido, como sugere Albuquerque ${ }^{11}$.

Esse resultado também ficou evidente quando os participantes foram solicitados a descrever a importância da TN. Apesar de 90\% ter julgado a TN importante para a saúde de sua criança, a maioria não soube descrever o por quê. Ainda que a pergunta do roteiro de entrevista pudesse ter interferido nas respostas positivas dos participantes, houve um número considerável de participantes que não sabiam reconhecer algum benefício na realização da TN.

Quanto ao resultado obtido referente à baixa demanda por mais informações sobre o Teste do Pezinho pelos participantes, uma possibilidade de explicação é que: a primeira pergunta (sobre a importância e a finalidade do teste) era feita antes de o teste ter sido realizado, em um momento no qual os cuidadores estavam aguardando em sala de espera o chamado para o teste; enquanto a segunda pergunta (sobre se gostaria de receber mais informações sobre o teste) foi feita após a realização do teste, geralmente no momento em que os cuidadores já queriam ir embora, estavam mais impacientes após o choro da criança. Uma outra hipótese que pode ser levantada em relação a este resultado é que a instrução recebida pelos participantes diz respeito somente a fazer o teste, e o comportamento de questionar a autoridade representada pela equipe de saúde não é estimulado em contextos de saúde pública. Pede-se para fazer determinado procedimento, mas sem esclarecer o quê fazer, nem porquê fazer.

A falta de conhecimento a respeito do Teste do Pezinho deveria ser suprida no momento da realização do mesmo, para enfatizar a importância do exame, bem como ratificar a neces- sidade de buscar o resultado, como preconiza o Manual de Normas Técnicas e Rotinas Operacionais do Programa de Triagem Neonatal ${ }^{1}$. Por mais que a unidade de referência realize busca ativa aos pacientes diagnosticados com alguma das patologias triadas, a dificuldade de acesso a essa população pode ocorrer devido à distância de seu local de moradia, problemas com os meios de comunicação etc, dificultando o início do tratamento preventivo.

A instrução fornecida pela unidade aos pais, sobre a busca pelo resultado do exame, indicava uma data a partir da qual o resultado estaria disponível. A equipe da Triagem também estava orientada para, nos casos em que o resultado do teste fosse alterado, haveria uma busca ativa pelo $\mathrm{RN}$ antes da data agendada para o retorno da criança à unidade, entretanto isto não era mencionado para os cuidadores, conforme foi relatado pelos participantes.

A ocupação do cuidador, bem como a sua renda familiar, não se mostraram variáveis que viessem a interferir nos resultados.

A alta hospitalar, bem como o tempo de internação do RN e a presença de intercorrências não se mostraram variáveis que por si só justificassem a alta freqüência de crianças realizando o teste no intervalo de 11 a 30 dias, e mesmo após 30 dias, encontrada neste estudo.

\section{CONCLUSÃO}

Os resultados obtidos por esta pesquisa apontam uma baixa compreensão de pais e/ou cuidadores acerca do Teste do Pezinho. A noção de que a Triagem Neonatal pode auxiliar na prevenção de sequielas de doenças crônicas, como a fenilcetonúria e o hipotireoidismo congênito, não estava bem estabelecida entre a maioria dos participantes deste estudo.

O provável estímulo antecedente controlador da resposta de levar o filho a fazer o teste, neste estudo, parece ter sido a instrução fornecida por autoridades como os profissionais de saúde. O reconhecimento de vantagens para o crescimento e desenvolvimento do RN, bem como a noção de promoção de saúde e qualidade de vida que pode- 
riam advir com a realização do teste e início de tratamento preventivo, não foram considerados como estímulos motivacionais pelos pais e/ou cuidadores.

Entretanto, se os pais e/ou cuidadores não tiverem repertório suficiente para analisar as contingências associadas ao comportamento de seguir ou não as instruções médicas, o comportamento de aderir às instruções não se torna estável, comprometendo o tratamento quando este for necessário.

\section{AGRADECIMENTOS}

Nossos agradecimentos à UREMIAUnidade de Referência Materno Infantil e do Adolescente, de Belém-PA, pela autorização e apoio na realização deste estudo; às auxiliares de pesquisa Bruna Carvalló e Lívia Melo, pelo auxílio na coleta dos dados; à médica Milena Caldato, pelo incentivo e parceria.

\begin{abstract}
Newborn screening, known mainly as PKU and CH screening or Guthrie test, is a public health strategy which aims at the prevention of mental sequels provoked by congenital hypothyroidism and phenylketonuria. These diseases do not usually cause symptoms during the first months of the child's life. However, if they are diagnosed precociously, there is a high probability that the treatment prevents its serious consequences. The test is performed in infants during their first 30 days of life, and their primary caregivers play a crucial role so that prevention occurs. The objective of this work was to study the characteristics of the people being assisted by a service of excellence in Newborn Screening located in the city of Belém, state of Pará, and to evaluate the understanding of parents and/or caregivers about the importance of the Guthrie Test. A questionnaire was applied to 200 participants, who had previously agreed to answer an interview script, and it was verified whether they returned to check the result of the test. The results indicated that most of the participants were not aware of the importance of the test as a resource to promote prevention in child's health.
\end{abstract}

Key words: Guthrie test. Newborn screening. Pediatric psychology. Prevention.

\section{REFERÊNCIAS}

1. Ministério da Saúde. Manual de normas técnicas e rotinas operacionais do programa de triagem neonatal. Brasília (DF); 2002.

2. Giusti MMC. A iniciativa pioneira da APAE em São Paulo. In: Medeiros Neto G, organizador. Hipotireoidismo congênito no Brasil: como era, como estamos, para onde vamos. São Paulo: Instituto da Tireóide; 2004. p. 31-6.

3. Carvalho TM. Programa nacional de triagem neonatal: um novo enfoque como programa de saúde pública. In: Medeiros Neto G, organizador. Hipotireoidismo congênito no Brasil: como era, como estamos, para onde vamos. São Paulo, SP: Instituto da Tireóide; 2004. p. 15-23.

4. Ministério da Saúde do Brasil. Portaria Ministerial no 822, de 06 de junho de 2001. Institui, no âmbito do Sistema Único de Saúde, o Programa Nacional de Triagem
Neonatal - PNTN. [acesso em 6 mar 2004]. Disponível em: http://dtr2001.saude.gov.br/ sas/PORTARIAS/Port2001/GM/GM-822.htm.

5. Setian N. Hipotireoidismo congênito. In: Setian N, editor. Endocrinologia pediátrica: aspectos físicos e metabólicos do recémnascido ao adolescente. 2 a ed. São Paulo: Sarvier; 2002. p. 259-68.

6. Johnson SB, Milstein SG. Prevention opportunities in health care settings. Am Psychol. 2003;58(67):475-81.

7. Guimarães SS. Psicologia da saúde e doenças crônicas. In: Kerbauy RR, organizador. Comportamento e saúde: explorando alternativas. Santo André: ArtBytes; 1999. p. 22-45.

8. Witter GP. Produção científica sobre estresse e prevenção. In: Witter GP, organizador.

Psicologia: tópicos gerais. Campinas: Alínea; 2002. p. 239-55.

9. Casseb MS. Prevenção em diabetes: efeito do treino de automonitoração na redução de fatores de risco [projeto de qualificação de mestrado - Programa de Pós-Graduação em 
Teoria e Pesquisa do Comportamento]. Belém: Universidade Federal do Pará; 2004.

10. Wallack L, Winkleby M. Primary prevention: a new look at basic concepts. Soc Sci Med. 1987;25(8):923-30.

11. Berlinguer G. Bioética da prevenção. Bioética. 1994;2(2):117-22.

12. Abreu-Rodrigues J, Sanabio-Heck ET. Instruções e auto-instruções: contribuições da pesquisa básica. In: Abreu CN, Guilhardi HJ, organizadores. Terapia comportamental e cognitivo-comportamental. São Paulo: Roca; 2005. p. 152-68.

13. Albuquerque LC. Definições de regras. In: Guilhardi HJ, organizador. Sobre comportamento e cognição. Santo André: ESETec; 2001. p. 132-40.

14. Ayres M, Ayres Jr M, Ayres DL, Santos AS. Bio Estat 3.0: aplicações estatísticas nas áreas das ciências biológicas e médicas. Belém: Sociedade Civil Mamirauá; Brasília: CNPq; 2003.

Recebido em 28/06/2006

Aprovado em 03/10/2006 